\title{
Absorption of Iron from Ferritin Is Independent of Heme Iron and Ferrous Salts in Women and Rat Intestinal Segments ${ }^{1-3}$
}

\author{
Elizabeth C. Theil, ${ }^{4,5 *}$ Huijun Chen, ${ }^{4,5,10}$ Constanza Miranda, ${ }^{6}$ Heinz Janser, ${ }^{7}$ Bernd Elsenhans, ${ }^{7}$ \\ Marco T. Núñez, ${ }^{8}$ Fernando Pizarro, ${ }^{6}$ and Klaus Schümann ${ }^{9}$ \\ ${ }^{4}$ Children's Hospital Oakland Research Institute, Oakland, CA; ${ }^{5}$ Department of Nutritional Sciences and Toxicology, University of \\ California, Berkeley, CA; ${ }^{6}$ Institute of Nutrition and Food Technology, Universidad de Chile, Santiago, Chile; ${ }^{7}$ Walther-Straub-Institut \\ for Pharmacology and Toxicology, Ludwig-Maximilians-Universität, Muenchen, Germany; ${ }^{8}$ Department of Biology, Faculty of Sciences, \\ Universidad de Chile, and Millennium Institute in Cell Dynamic and Biotechnology, Santiago, Chile; and ${ }^{9}$ Research Center for Nutrition \\ and Food Sciences, Biochemistry Unit, Technische Universität München, Freising-Weihenstephan, Germany
}

\begin{abstract}
Ferritin iron from food is readily bioavailable to humans and has the potential for treating iron deficiency. Whether ferritin iron absorption is mechanistically different from iron absorption from small iron complexes/salts remains controversial. Here, we studied iron absorption (RBC $\left.{ }^{59} \mathrm{Fe}\right)$ from radiolabeled ferritin iron $(0.5 \mathrm{mg})$ in healthy women with or without nonferritin iron competitors, ferrous sulfate, or hemoglobin. A 9-fold excess of non-ferritin iron competitor had no significant effect on ferritin iron absorption. Larger amounts of iron (50 mg and a 99-fold excess of either competitor) inhibited iron absorption. To measure transport rates of iron that was absorbed inside ferritin, rat intestinal segments ex vivo were perfused with radiolabeled ferritin and compared to perfusion with ferric nitrilotriacetic (Fe-NTA), a well-studied form of chelated iron. Intestinal transport of iron absorbed inside exogenous ferritin was $14.8 \%$ of the rate measured for iron absorbed from chelated iron. In the steady state, endogenous enterocyte ferritin contained $>90 \%$ of the iron absorbed from Fe-NTA or ferritin. We found that ferritin is a slow release source of iron, readily available to humans or animals, based on RBC iron incorporation. Ferritin iron is absorbed by a different mechanism than iron salts/chelates or heme iron. Recognition of a second, nonheme iron absorption process, ferritin endocytosis, emphasizes the need for more mechanistic studies on ferritin iron absorption and highlights the potential of ferritin present in foods such as legumes to contribute to solutions for global iron deficiency. J. Nutr. 142: 478-483, 2012.
\end{abstract}

\section{Introduction}

Intestinal iron absorption is the main step regulated for body iron homeostasis because of low iron excretion $(1,2)$. Mechanistic studies of intestinal iron absorption have focused heavily on $\mathrm{Fe}^{2+}$ transport by DMT1, a proton coupled transporter of a number of divalent cations $(1,3)$, and on heme absorption by the folate-heme transporter PCFT/HCP1 (4). Earlier studies showed that in cultured intestinal cells, exogenous ferritin, which is a nanoprotein that synthesizes caged ferric oxide minerals containing thousands of iron atoms (5), is taken up by clathrin-dependent endocytosis and efficiently releases its iron into the cytoplasmic labile iron pool (6). Ferritin is abundant in

\footnotetext{
${ }^{1}$ Supported in part by NIH grant DK20251 (H.C. and E.C.T.), the CHORI Foundation (E.C.T.), Fondecyt-Chile (project no. 1050068 to C.M., M.T.N., F.P.), and the Hildegard-Grunow-Foundation (B.E., H.J., and K.S.).

${ }^{2}$ Author disclosures: E. C. Theil, H. Chen, C. Miranda, H. Janser, B. Elsenhans, M. T. Núñez, F. Pizarro, and K. Schumann, no conflicts of interest.

${ }^{3}$ Supplemental Tables 1-6 are available from the "Online Supporting Material" link in the online posting of the article and from the same link in the online table of contents at jn.nutrition.org.

${ }^{10}$ Present address: Medical School of Nanjing University, Mengminwei Building, 19th floor, 22 Hankou RD., Nanjing, China 210093.

* To whom correspondence should be addressed. E-mail: etheil@chori.org.
}

legume seeds (7-9). If the iron atoms contained in intact ferritin were readily absorbed by humans in vivo, as indicated by cell culture experiments $(6,10,11)$, thousands of protein-coated iron atoms would be absorbed per transport event. Human absorption of iron inside ferritin protein would contrast with the transport of single iron atoms by DMT1 as $\mathrm{Fe}^{2+}$ ions or by PCFT/HCP1 in heme. This study addresses the question of whether iron present inside ferritin is converted to single iron atoms in the stomach or intestinal lumen in vivo, or if ferritin is absorbed as the intact protein-iron complex. To answer this question, we used two experimental approaches. First, we determined if unlabeled iron provided as ferrous sulfate decreases absorption of labeled ferritin iron in humans, which would indicate that ferritin iron and iron from ferrous sulfate compete for the same absorption mechanism; we also used hemoglobin as a competitor for intracellular iron release. Second, we compared exogenous ${ }^{59} \mathrm{Fe}$ - ferritin to a ferric chelate $\left({ }^{59} \mathrm{Fe}-\mathrm{NTA}^{11}\right)$, which is an established model of inorganic iron

\footnotetext{
${ }^{11}$ Abbreviations used: Fe-NTA, ferric nitrilotriacetic acid; GR, gastric resistant; HoSF, horse spleen ferritin; INTA, Institute of Nutrition and Food Technology; non-GR, nongastric resistant; TCA, trichloroacetic acid.
} 
absorption (12-14), in perfused, isolated rat intestinal segments, analyzing mucosal iron accumulation, iron transport, and intracellular iron distribution.

\section{Methods}

\section{Radiolabeled materials}

Fe isotopes $\left({ }^{55} \mathrm{Fe}\right.$ and $\left.{ }^{59} \mathrm{Fe}\right)$ were obtained from NEN/Perkin Elmer for the human studies and from RI Consultants LLC for the rat studies. Empty ferritin protein cages, prepared by extensive dialysis against thioglycolic acid, were mineralized with radiolabeled Fe as previously described $(6,15,16) .{ }^{59} \mathrm{Fe}-\mathrm{NTA}$ was prepared by adding ${ }^{59} \mathrm{Fe}$ to a solution of NTA to obtain a molar Fe:NTA ratio of 1:2 (17).

\section{Human studies}

Volunteers. A total of 73 healthy women between 35 and 45 y of age were randomly assigned to one of the five iron absorption studies. The studies were conducted between July, 2005 and July, 2008. All the women lived in Santiago, Chile; they were recruited from the community living near the INTA. None were pregnant or lactating, and all were using intrauterine devices for contraception at the time of the study. Exclusion criteria were obesity (BMI $>30$ ), micronutrient supplementation in the last 6 mo, and any known acute or chronic disease, as evaluated by a physician. All of the women signed an informed consent form approved by the Ethics Committee of INTA. Doses of radioactive isotopes used were approved by the Chilean Commission of Nuclear Energy.

Iron status. Iron nutritional status was assessed by the values of hemoglobin concentration, erythrocyte mean corpuscular volume, free RBC protoporphyrin, transferrin saturation, and serum ferritin. The hematological categories used were previously described (18). Iron status variables were similar among the groups. Data on individuals are provided in Supplemental Table 1. To assess fluctuations in daily iron absorption, ${ }^{59} \mathrm{Fe}$-ferritin or ${ }^{55} \mathrm{Fe}$-ferritin were administered on two consecutive days, as described in detail in "Study design" (Table 1). In addition, to minimize variations, the participants fasted overnight. After ingesting the test capsules at $0800 \mathrm{~h}$, they consumed no solid food for $3-4 \mathrm{~h}$. The dose of ferritin iron used $(0.5 \mathrm{mg})$ was physiological $(19,20)$, whereas the doses of nonheme iron and heme iron $(4.5-49.5 \mathrm{mg})$ encompassed both the physiological and supra-physiological range (21).

Iron delivery capsules. To distinguish between effects on release of ferritin and the iron competitor in the stomach or the intestine, two types of capsules were used. Non-GR capsules were gelatin capsules obtained from Reutter. GR capsules were gelatin capsules covered with the enteric polymer L30 D55 from Eudragit (Roehm). Non-GR capsules release the contents in the stomach, whereas GR capsules release the contents in the intestine.

Hemoglobin. Hemoglobin was obtained from New Zealand rabbit $\mathrm{RBC}$ by using a protocol approved by the Bioethics Committee for
Animal Experimentation of INTA. RBC were washed three times with physiological saline, frozen, and lyophilized. The iron content was determined by atomic absorption spectroscopy.

Study design. Table 1 shows the protocols and the doses of iron administrated for the five studies. Supplemental Tables 2-6, corresponding to studies A-E, show individual data. On d 1 and 14, the participants ingested $0.5 \mathrm{mg}$ elemental iron as ferritin labeled with $1 \mu \mathrm{Ci}{ }^{59} \mathrm{Fe}$. On d 2 and 15 , they ingested $0.5 \mathrm{mg}$ elemental iron as ferritin labeled with $3 \mu \mathrm{Ci}$ of ${ }^{55} \mathrm{Fe}$. Blood samples were taken on $\mathrm{d} 14$ to determine absorption on $\mathrm{d}$ 1 and 2 and on $\mathrm{d} 28$ to determine absorption from $\mathrm{d} 14$ and 15 . During $\mathrm{d}$ 2,14 , and 15 , ferritin containing radiolabeled iron was administered together with different amounts of iron as ferrous sulfate (studies A and C), hemoglobin (study B), or ferrous sulfate plus ascorbic acid (study D). In studies $\mathrm{A}$ and $\mathrm{B}$, the compounds were administered in non-GR capsules, in study C they were administered in GR capsules, and in study $\mathrm{D}$ in either non-GR or GR capsules. In the studies using ${ }^{59} \mathrm{FeSO}_{4}$, the volunteers ingested $0.5 \mathrm{mg}{ }^{59} \mathrm{FeSO}_{4}$ on two consecutive mornings (d 1: ${ }^{59} \mathrm{FeSO}_{4}$ alone; $\mathrm{d} 2:{ }^{59} \mathrm{FeSO}_{4}$ plus $9.5 \mathrm{mg}$ Fe as ferritin). Compounds were administered in aqueous solution. RBC radioactivity was determined on duplicate samples from venous blood according to technique of Eakins and Brown (22).

Iron absorption. Iron absorption was calculated using blood volumes estimated from height and weight (23) and assuming that $80 \%$ of radioisotope was incorporated into $\mathrm{RBC}(24)$.

\section{Animal studies}

Rats. The experiments were performed using best practices of animal care; the studies were approved by the CHORI Institutional Animal Care and Use Committee. Male Sprague-Dawley rats younger than 6 mo of age weighing $372 \pm 17 \mathrm{~g}$ were housed in macrolone cages with a 12-hlight/-dark cycle. Rats were fed a standard diet (no. 2918 Teklad Harlan Global Diet) sterilized by irradiation. Rats consumed autoclaved tap water ad libitum. Duodenal and jejunal segments from 5 rats were perfused with ${ }^{59} \mathrm{Fe}$-ferritin. The data were compared to data from 5 or 6 rats perfused with ${ }^{59} \mathrm{Fe}-\mathrm{NTA}$ in earlier experiments $(13,25) ; 2$ rats were used as controls in this experiment. Body iron status was determined by analyzing nonheme iron in rat liver (26). Liver nonheme iron did not vary significantly among the groups.

Ex vivo perfusion of isolated rat intestinal segments and measurement of mucosa to serosa ${ }^{59} \mathrm{Fe}$ transport. Excision of duodenal and jejunal segments occurred under isoflurane anesthesia (VetEquip). The duodenal segments were the $\sim 8$-cm length between the pylorus and Treitz ligament and the jejunal segments were the adjacent $10 \mathrm{~cm}$ of intestine. Following excision of the intestinal segments, rats were killed with isoflurane. The isolated intestinal segments were perfused from the luminal side. ${ }^{59} \mathrm{Fe}$ transfer rates from the intestinal lumen to the serosal fluid discharge were quantified as previously described $(13,25)$. A constant rate of water transport and active glucose

TABLE 1 Human study protocols ${ }^{1}$

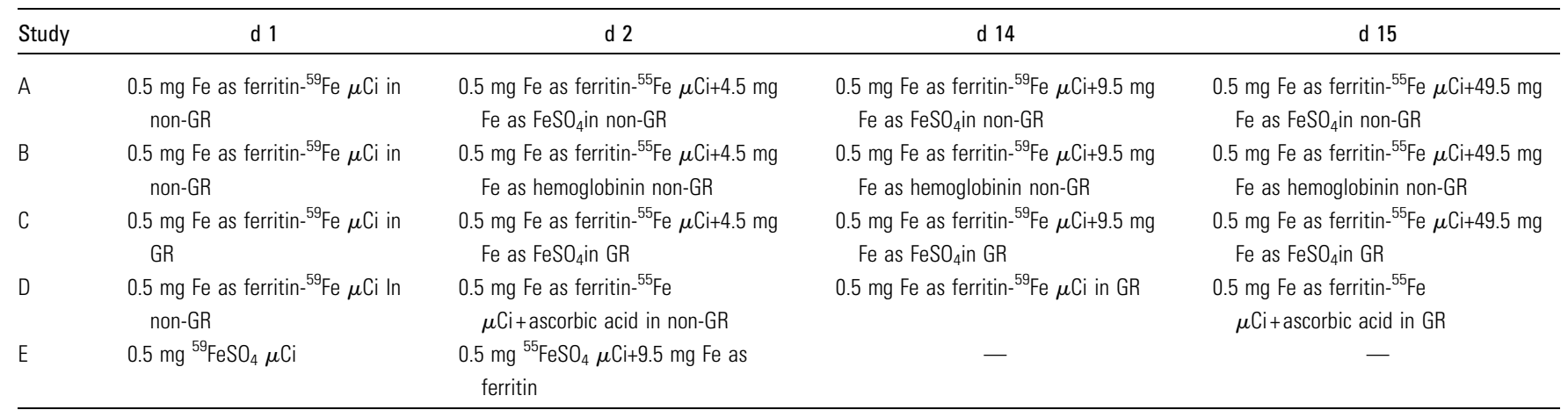

\footnotetext{
${ }^{1}$ The data of individuals and the statistical analyses are found in the footnotes to Supplemental Tables 1-6. GR, gastric restraint.
} 
transport were the criteria for vitality during ex vivo perfusion. The serosal fluid discharge was sampled at 15 -min intervals and weighed. To determine mucosa to serosa ${ }^{59} \mathrm{Fe}$ transport, ${ }^{59} \mathrm{Fe}$-labeled ferritin or ${ }^{59} \mathrm{Fe}-\mathrm{NTA}\left(10 \mu \mathrm{mol} \mathrm{Fe} / \mathrm{L} ;{ }^{59} \mathrm{Fe} \sim 0.2 \mathrm{mCi} / \mathrm{L}\right)$ was added to the perfusate after fluid absorption had reached a steady state, at $\sim 10 \mathrm{~min}$ after start of ex vivo perfusion.

Rat intestinal cell isolation. At the end of the perfusion experiments, cells from ${ }^{59} \mathrm{Fe}$-labeled mucosal jejunal and duodenal segments were obtained by scraping with glass slides, transferring to small tubes, washing with physiological saline, sedimenting, and freezing at $-80^{\circ} \mathrm{C}$ until use. The cells thus obtained were substantially free of contamination by cells of the lamina propria, muscle, and blood vessels and were mostly enterocytes, with some goblet cells, Paneth cells, and leukocytes. Mucosal cells were homogenized with polypropylene pestles in $120 \mu \mathrm{L}$ of cold PBS containing protease inhibitors (1206893; Roche Molecular Biochemicals). Cell lysis was achieved by passing the homogenate through a 27 -gauge needle, followed by centrifugation at $21,000 \times g$ for $20 \mathrm{~min}$ at $4^{\circ} \mathrm{C}$ to obtain the soluble cell extract as the supernatant fraction. ${ }^{59} \mathrm{Fe}$ was determined, as for the perfusates, in cell pellets and an aliquot of the cytoplasmic extracts.

Distribution of ${ }^{59} \mathrm{Fe}$ in rat enterocytes. The distribution of ${ }^{59} \mathrm{Fe}$ between protein and low-molecular weight components in the soluble extracts of mucosal cells was determined by precipitation of the extracts with $10 \%$ cold TCA and the measurement of ${ }^{59} \mathrm{Fe}$ in the pellets (protein) and the TCA-soluble fraction as previously described (6).

To characterize ${ }^{59} \mathrm{Fe}$ proteins in soluble (cytosolic) extracts of mucosal cells, samples were fractionated by native PAGE $(4-12 \%$ polyacrylamide gradient gels) with Tris-glycine running buffer (Invitrogen). Migration of ${ }^{59} \mathrm{Fe}$-containing proteins was detected by autoradiography and quantified with IMAGEQUANT software.

\section{Statistical analyses}

Human data were tested by one factor ANOVA and the post hoc Dunnett's test using Graphpad. Rat data were analyzed by the unpaired $t$ test. Differences were considered significant at $P<0.05$.

\section{Results}

A 9-fold excess of ferrous sulfate has no effect on ferritin iron absorption. Effects of ferrous sulfate on iron absorption from ${ }^{59} \mathrm{Fe}$-ferritin were examined to determine if the iron in ferritin was absorbed by the same mechanism as ferrous sulfate. Because the total amount of iron added was $>5 \mathrm{mg}$, saturation kinetics were maintained.

Unlabeled ferrous sulfate had no effect on the absorption of $0.5 \mathrm{mg}$ of ${ }^{59} \mathrm{Fe}$ in ferritin at a ratio of 9:1 (4.5 $\mathrm{mg} \mathrm{FeSO}_{4}$ and $0.5 \mathrm{mg}{ }^{59} \mathrm{Fe}$ as ferritin iron) in non-GR capsules (Fig. 1; data from individuals are provided in Supplemental Table 2). Similar results were obtained with GR capsules at a 9:1 ratio (Fig. 1; data from individuals are in Supplemental Table 4). At higher ratios of iron competitor:ferritin iron, the results were more complex. For example, with a ratio of 19:1 (9.5 mg $\mathrm{FeSO}_{4}$ and $0.5 \mathrm{mg}{ }^{55}$ Fe-ferritin) administered in capsules dissolved in the stomach, there was no significant effect on ${ }^{55} \mathrm{Fe}$ absorption (Fig. 1; Supplemental Table 2). However, when GR capsules were used, there was inhibition $(P<0.05)$ (Fig. 1; Supplemental Table 4). Individual variations in absorbance at the $19: 1$ ratio $(9.5 \mathrm{mg}$ $\mathrm{FeSO}_{4}$ and $0.5 \mathrm{mg}{ }^{55} \mathrm{Fe}$-ferritin) were large (Supplemental Table 2), possibly because with a total of $10 \mathrm{mg}$ of supplemental iron, the variable amounts of iron eaten in other foods by the women brings some but not all individuals to iron repletion. In the reverse experiment, using ${ }^{55} \mathrm{FeSO}_{4}$ and unlabeled ferritin iron as the competitor, ${ }^{55} \mathrm{Fe}$ absorption from $\mathrm{FeSO}_{4}$ was inhibited when $0.5 \mathrm{mg}$ of ${ }^{55} \mathrm{FeSO}_{4}$ was administered with $9.5 \mathrm{mg}$ of ferritin iron

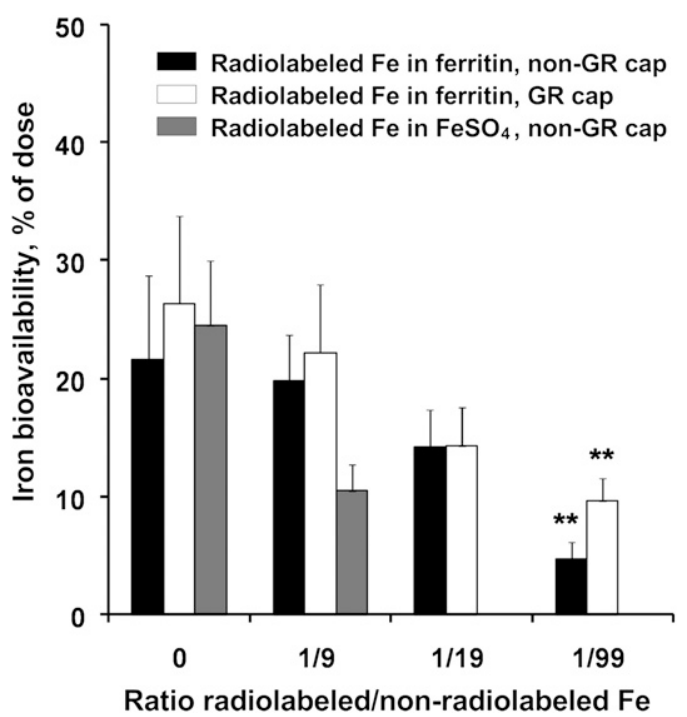

FIGURE 1 Ferritin iron absorption by healthy women administered ferrous sulfate at 0-1:99 molar ratios in GR and non-GR capsules. Individual data are in Supplemental Tables 2, 4, and 6. Values are mean $\pm \mathrm{SD}, n=13$ or 14 . ${ }^{*}$ Different from $0, P<0.01$. GR, gastric resistant; non-GR, nongastric resistant.

(Fig. 1; Supplemental Table 6). This inhibition could be due to a mucosal block in iron absorption generated by ferritin-derived intracellular iron from $10 \mathrm{mg}$ of administered iron. When the total supplemented iron was very high $\left(50 \mathrm{mg}\right.$; $\mathrm{FeSO}_{4}$ :ferritin iron, 99:1), radiolabeled ferritin iron absorption decreased to $20-32 \%$ of the control under all the conditions tested $(P<0.01)$ (Fig. 1; Supplemental Tables 2 and 4).

Ascorbate, added to reduce ferric to ferrous iron, had no effect on the absorption of iron from ferritin (Fig. 2A; Supplemental Table 5). In solution, where competing reactions with ascorbate are minimized, ascorbate can release $\sim 5 \%$ of the iron in ferritin (27).

Hypothetically, digestion of the ferritin protein cage and mixing of ferritin radiolabeled iron (after reduction and mineral dissolution) with a 9-fold excess of ferrous sulfate would decrease absorption of the radiolabeled iron by $90 \%$. Thus, the absence of any effect of $\mathrm{FeSO}_{4}$ at a 9:1 ratio with ferritin (Fig. 1; Supplemental Table 2) indicates that ferritin mineral was not reduced and the protein was not degraded to release iron during luminal digestion. A similar result was obtained when ascorbate was added (Fig. 2A; Supplemental Table 4).

A 9-fold excess of hemoglobin iron has no effect on ferritin iron absorption. Because heme iron is absorbed by a different mechanism than ferrous sulfate iron and because heme iron is released intracellularly after heme oxygenase action (4), contrasting with ferrous sulfate, heme iron may compete more effectively with ferritin iron than ferrous sulfate. However, a 9fold excess of heme iron had no significant effect on iron absorption from ${ }^{59}$ Fe-labeled ferritin (Fig. 2B; Supplemental Table 4). A decrease in ferritin iron absorption was found at a heme Fe:ferritin Fe ratio of 19:1 $(P<0.05)$ and 49:1 $(P<0.01)$ (Fig. 2B; Supplemental Table 4). Such results suggest that signals from excess iron converge in the cell, regardless of the iron source, to activate common regulatory mechanisms $(28,29)$.

Iron from ferritin moved across rat intestine more slowly than from Fe-NTA. Iron absorption and transport across the intestine from exogenous ferritin could be directly determined in 

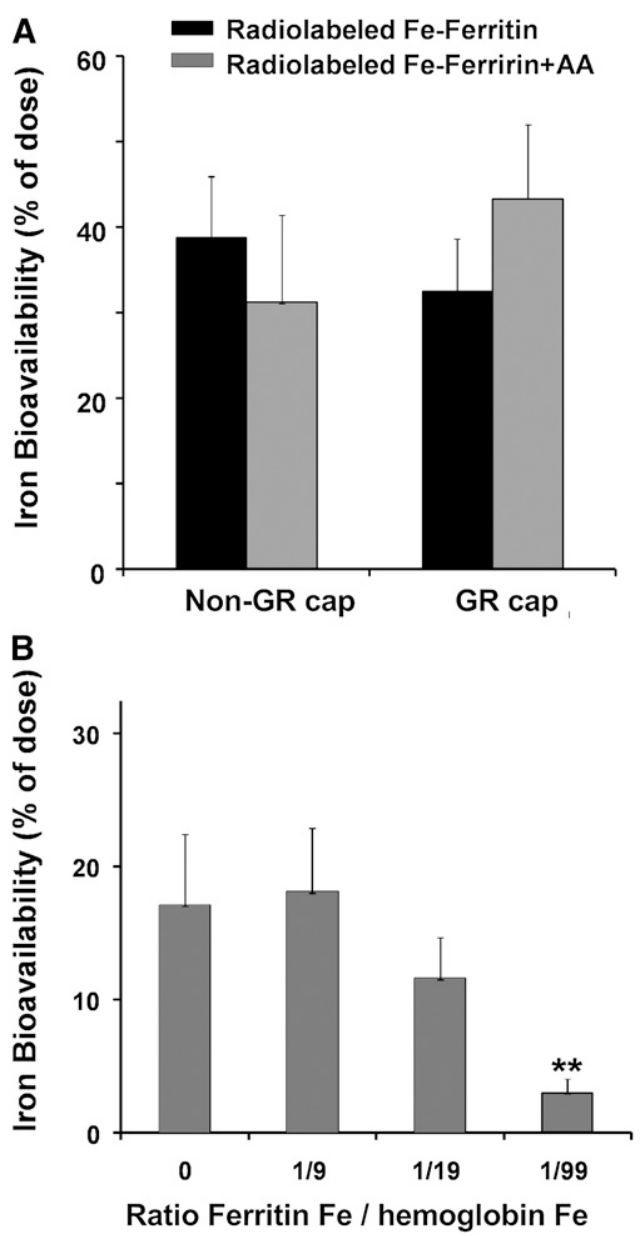

FIGURE 2 Ferritin iron absorption by healthy women administered ascorbic acid in GR or non-GR capsules $(A)$ or hemoglobin iron at 0-1:9 in non-GR capsules $(B)$. Values are the mean $\pm \mathrm{SD}, n=15(A)$ or 13 $(B)$. Data for individuals are in Supplemental Tables 5 and 3, respectively. ${ }^{*}$ Different from $0, P<0.01$. GR, gastric resistant; non-GR, nongastric resistant.

rat intestinal segments perfused ex vivo and compared to the well-studied ferric chelate, Fe-NTA (12-14). The rate of ${ }^{59} \mathrm{Fe}$ transport from exogenous ferritin to the luminal side was equivalent (Table 2) in the duodenum and jejunum, contrasting with ${ }^{59} \mathrm{Fe}-\mathrm{NTA}$, where transport to the luminal side was significantly faster in the duodenum (Table 2).Tissue stability (water transport) and vitality (glucose transport), measured every $15 \mathrm{~min}$, remained in the normal range throughout the experiments. ${ }^{59} \mathrm{Fe}$ transport to the luminal side of the intestinal segments was constant during the 2-h perfusion.

Iron from ferritin is transported across both the duodenum and the upper jejunum (Table 2). The transport rate for ${ }^{59} \mathrm{Fe}$ from perfused ferritin was significantly lower than from perfused Fe-NTA in both duodenum and jejunum (Table 2). Two properties of iron absorbed from ferritin and chelated iron likely account for the differences: 1) different uptake mechanisms (DMT1 transporter vs. clathrin-dependent endocytosis); and 2) steps required ferritin for iron to enter the cytoplasm (reduction/dissolution of the ferritin iron mineral and iron ion transport out of the endosome).

Retained iron absorbed from perfusate ferritin is present mainly in enterocyte ferritin. The examination of ${ }^{59} \mathrm{Fe}$ absorbed by cells in the intestine after ex vivo perfusion showed
TABLE $2{ }^{59} \mathrm{Fe}$ absorbed in ${ }^{59} \mathrm{Fe}-\mathrm{HoSF}$ by rat duodenal and jejunal segments perfused ex vivo ${ }^{1}$

\begin{tabular}{|c|c|c|}
\hline & Duodenum & Jejunum $^{2}$ \\
\hline \multicolumn{3}{|l|}{${ }^{59} \mathrm{Fe}$-labeled ferritin } \\
\hline$n$ & 5 & 6 \\
\hline${ }^{59} \mathrm{Fe}$ transfer, $\mathrm{pmol} \cdot \mathrm{cm}^{-1} \cdot 2 \mathrm{~h}^{-1}$ & ${ }^{*} 93 \pm 53$ & ${ }^{*} 67 \pm 58$ \\
\hline${ }^{59} \mathrm{Fe}$ mucosa load, $\mathrm{pmol} \cdot \mathrm{cm}^{-1}$ & ${ }^{*} 177 \pm 8$ & ${ }^{*} 209 \pm 65$ \\
\hline Water transfer, $\mathrm{pmol} \cdot \mathrm{cm}^{-1} \cdot 2 \mathrm{~h}^{-1}$ & $167 \pm 20$ & $159 \pm 25$ \\
\hline \multicolumn{3}{|l|}{${ }^{59} \mathrm{Fe}-\mathrm{NTA}$} \\
\hline$n$ & 2 & 2 \\
\hline${ }^{59} \mathrm{Fe}$ transfer, ${ }^{3} \mathrm{pmol} \cdot \mathrm{cm}^{-1} \cdot 2 \mathrm{~h}^{-1}$ & $630 \pm 79$ & $353 \pm 177$ \\
\hline${ }^{59} \mathrm{Fe}$ mucosa load, ${ }^{3} \mathrm{pmol} \cdot \mathrm{cm}^{-1}$ & $1590 \pm 31$ & $1150 \pm 31$ \\
\hline Water transfer, $\mathrm{pmol} \cdot \mathrm{cm}^{-1} \cdot 2 \mathrm{~h}^{-1}$ & $212 \pm 33$ & $210 \pm 3$ \\
\hline$n$ & 5 & - \\
\hline${ }^{59} \mathrm{Fe}$ transfer, ${ }^{4} \mathrm{pmol} \cdot \mathrm{cm}^{-1} \cdot 2 \mathrm{~h}^{-1}$ & $1180 \pm 300$ & - \\
\hline$n$ & 6 & 6 \\
\hline${ }^{59} \mathrm{Fe}$ transfer, ${ }^{4} \mathrm{pmol} \cdot \mathrm{cm}^{-1} \cdot 2 \mathrm{~h}^{-1}$ & $650 \pm 110$ & $300 \pm 84$ \\
\hline
\end{tabular}

${ }^{1}$ Values are mean $\pm \mathrm{SD} .{ }^{*}$ Different from Fe-NTA, $P<0.01$. HoSF, horse spleen ferritin.

${ }^{2}$ Upper $10 \mathrm{~mm}$ of the jejunum. After perfusion, based on the water and glucose transfer rates, one duodenal segment had lost vitality and the data from that sample was not used.

${ }^{3}$ The values for Fe-NTA are significantly different from the ferritin values, $P<0.01$, $t$ test.

${ }^{4}$ Data are from (13) or (25); the values, analyzed by the $t$ test, differ significantly from ferritin, $P<0.01$.

that accumulation of iron from ${ }^{59} \mathrm{Fe}-\mathrm{NTA}$ was higher than for ${ }^{59} \mathrm{Fe}$-ferritin in both duodenum (8-fold) and jejunum (4-fold) (Fig. 3). However, the percent soluble ${ }^{59} \mathrm{Fe}$, i.e., extractable, cytosolic ${ }^{59} \mathrm{Fe}$, was similar (Fig. 3). Because the amount of nonextractable ${ }^{59} \mathrm{Fe}$-iron is different for exogenous Fe-NTA and exogenous ferritin but extractable cytosolic enterocyte iron is the same (Fig. 3), it is important in future investigations to determine the relationship of both extractable and nonextractable enterocyte iron to intracellular iron transport and export.

Cytosolic ${ }^{59} \mathrm{Fe}$ inside the rat intestinal cells, after luminal perfusion with HoSF, is almost entirely in protein in either duodenum or jejunum cells (Fig. 4). The ${ }^{59} \mathrm{Fe}$ protein had an electrophoretic migration close to, but distinct from, HoSF (Fig. 4). The mobility differences between the ${ }^{59} \mathrm{Fe}$ in cytosolic proteins and HoSF indicate that the ${ }^{59} \mathrm{Fe}$ was not in the HoSF

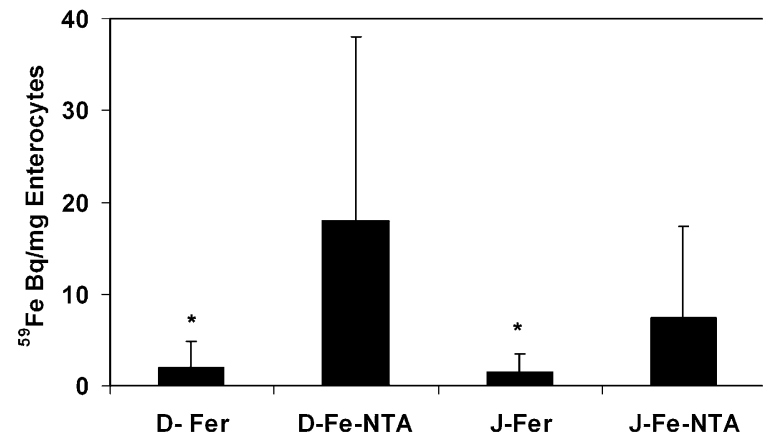

FIGURE 3 Accumulation and distribution of ${ }^{59} \mathrm{Fe}$ in cells, mainly enterocytes, from rat duodenum and jejunum perfused ex vivo with ${ }^{59} \mathrm{Fe}$-ferritin or ${ }^{59} \mathrm{Fe}-\mathrm{NTA}$. The data are the mean $\pm \mathrm{SD}, n=2$ or 3 . *Different from corresponding Fe-NTA, $P<0.01$. Note that the distribution of ${ }^{59} \mathrm{Fe}$ in the soluble (buffer-extractable) part of the cells and in proteins (TCA precipitable) was indistinguishable for perfused ${ }^{59}$ ferritin and ${ }^{59} \mathrm{Fe}-\mathrm{NTA}$ in duodenum and jejunum. Values were mean \pm $\mathrm{SD}, n=6,95.5 \pm 4.10 \%$ (ferritin) and, $n=4,92.8 \pm 1.88 \%$ (Fe-NTA). Fe-NTA, ferric nitrilotriacetic acid; TCA, trichloroacetic acid. 
of the perfusate but was released from HoSF inside the cells and incorporated into the endogenous, enterocyte ferritin iron mineral.

\section{Discussion}

The high bioavailability of iron in food ferritin such as soybean is largely accepted $(9,30)$. However, knowledge of how ferritin iron is absorbed has been lacking. Whether ferritin iron in humans is absorbed by the clathrin-dependent endocytic mechanism, as observed in cultured human cells (6), or is absorbed as part of the inorganic iron pool after digestion during passage through the stomach has been unresolved. The results presented here show that in women volunteers, ingested ferritin survived both gastric digestion and luminal digestion largely intact, because absorption of ferritin iron was unaffected by either nonheme or heme iron competitors at usual dietary ion concentrations.
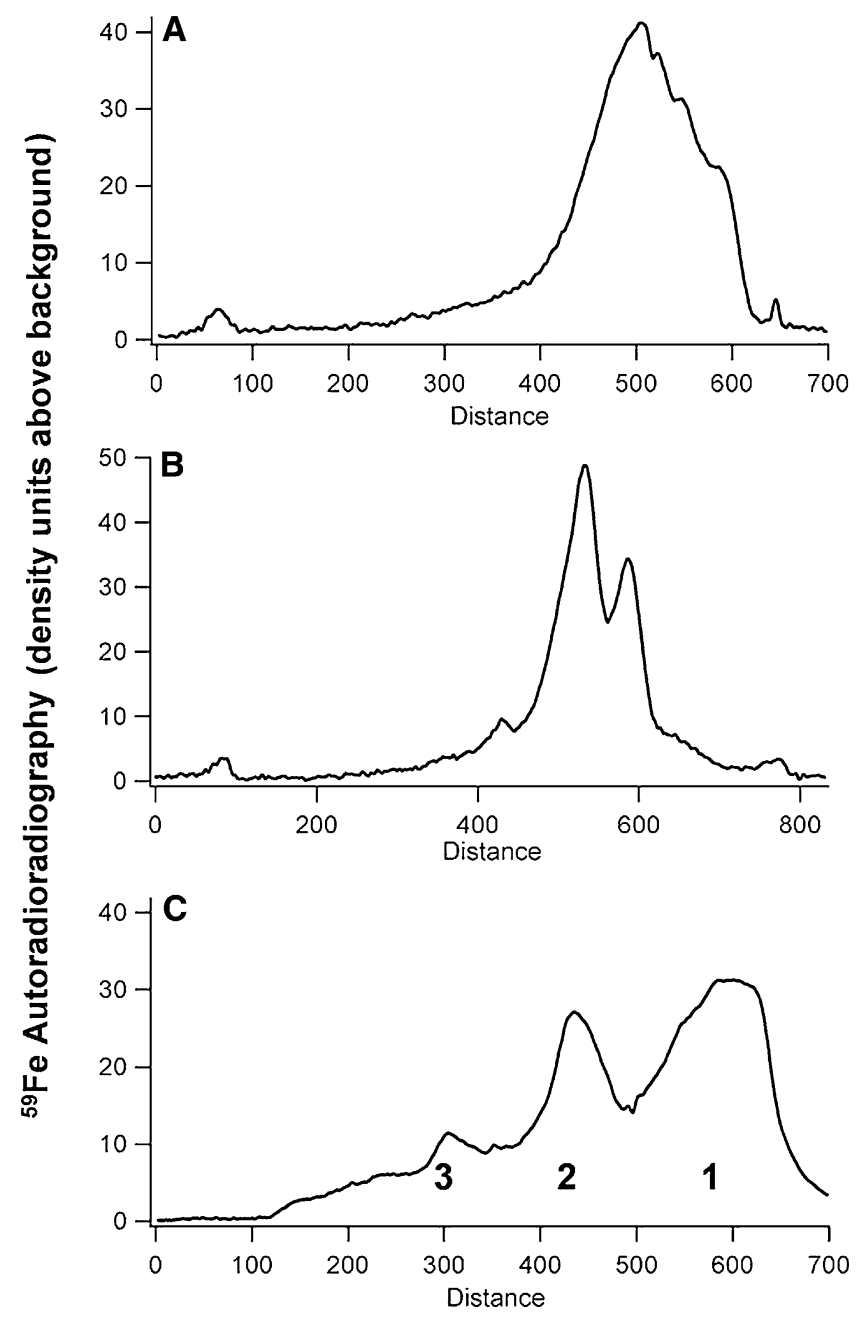

\section{Mobility of ${ }^{59} \mathrm{Fe}$ (soluble fraction)}

FIGURE 4 Distribution of ${ }^{59} \mathrm{Fe}$ in the cytosolic proteins of cells, mainly enterocytes, from rat duodenum $(A)$ and jejunum $(B)$ perfused ex vivo with ${ }^{59} \mathrm{Fe}$-ferritin or ${ }^{59} \mathrm{Fe}-\mathrm{NTA}$. (C) ${ }^{59} \mathrm{Fe}-\mathrm{HoSF}$, run at the same time. ${ }^{59} \mathrm{Fe}$ radioactivity was detected by autoradiography after native electrophoretic separation of soluble, cytoplasmic proteins $(400 \mu \mathrm{g})$. (C) ${ }^{59} \mathrm{Fe}-\mathrm{HoSF}$, run at the same time. The cell samples described in Figure 3 were used. Higher order complexes of ferritin cages; 1 : ferritin (24 subunits), 2: ferritin dimer (48 subunits); 3: ferritin trimer (96 subunits). Fe-NTA, ferric nitrilotriacetic acid; HoSF, horse spleen ferritin.
Because iron from $\mathrm{FeSO}_{4}$ is absorbed by DMT1 (1), the absence of competition by a 9 -fold excess of iron as $\mathrm{FeSO}_{4}$ on iron absorption from ferritin indicates that ferritin iron absorption does not depend on DMT1. The new data complement those obtained earlier in cultured, human epithelial (Caco-2) cells, where it was shown that ferritin enters cells by receptormediated, clathrin-dependent endocytosis (6), as confirmed more recently in cultured mouse epithelial (TCMK-1) cells (31).

Heme iron and ferritin iron must enter enterocytes by different mechanisms, even though the iron they carry is released inside the intestinal cells, because hemoglobin iron did not affect the absorption of ferritin iron in the range of normal iron supplementation dosages. Thus, each iron source, heme, or small nonheme iron salt/chelate, or large nonheme iron in ferritin is recognized by different, intestinal membrane receptors/transporters. However, when very large amounts of iron (10-50 mg) were provided as either hemoglobin or nonheme ferrous iron, absorption of ferritin iron decreased. Such effects can be due to rapid changes in receptor transporters on the apical side of the intestine $(29,32,33)$, which can be complemented by changes in enterocyte ferroportin activity and iron export. Such compensatory mechanisms lower entry of excess iron into the body at high iron doses.

Compared to chelated nonheme iron (Fe-NTA), ferritin iron is a natural, slow release iron source. The rate of transport of ferritin iron across the rat intestine was slower than for chelated ferric iron (Fe-NTA), although in whole body studies here and elsewhere, ferritin iron is incorporated into new RBC at about the same rates as nonheme iron salts $(15,34)$. When food (exogenous) ferritin enters intestinal cells in endosomes, the ferritin protein cage is digested and the iron mineral dissolved before crossing the endosomal membrane to enter the cytoplasmic iron pool. In spite of the differences in the intracellular processing of ferritin iron compared to ferrous sulfate, Fe-NTA, or hemoglobin, when the steady state was attained in the perfused intestinal segments studied here, iron from the cytoplasmic pool of the intestinal cells was distributed very similarly for both ${ }^{59} \mathrm{Fe}$-ferritin and chelated iron $\left({ }^{59} \mathrm{Fe}-\mathrm{NTA}\right)$. All the ${ }^{59} \mathrm{Fe}$ in the soluble fractions of the intestinal cells had been incorporated into protein with the properties of enterocyte ferritin. The importance of enterocyte ferritin in intestinal iron metabolism, indicated by the results with rat intestinal duodenal and jejunal segments ex vivo is complemented by two recent studies, one using mathematical modeling (35) and the other using targeted gene deletion of murine intestinal ferritin $\mathrm{H}(36)$. In the mathematical model (35), duodenal ferritin was the main regulator of the cellular labile iron pool and of the iron available for transport to the serosal side. In the mouse intestinal gene deletion study (36), loss of intestinal ferritin led to increased body iron stores, increased transferrin saturation, and increased duodenal ${ }^{59} \mathrm{Fe}$ absorption, emphasizing the important role of endogenous, intestinal cell ferritin in iron absorption and homeostasis.

There are several implications for iron nutrition that arise from the recognition of ferritin as a distinctive source of absorbable iron. First, the slow iron release properties of ferritin iron described here could protect intestinal cells from oxidative damage caused by some conventional iron supplements (37) and the coincident effects on inflammatory bowel diseases $(11,38)$. Second, because ferritin iron is internalized by a different mechanism than small inorganic iron salts/chelates or heme, supplementation with ferritin iron might be effective in treating iron deficiency anemias refractive to the usual iron treatments. Third, from a public health standpoint, ferritin-rich legume 
seeds, readily accessible but often consumed in amounts too small to prevent iron deficiency, can play a role in the lives of the $>2$ billion people for whom iron deficiency remains a problem in spite of decades of intense efforts toward mitigation. The absence of mechanistic answers to questions about the process of ferritin iron absorption does not prevent the use of ferritin for nutrition. Dietary ferritin is a distinct, nonheme source of absorbable iron that can be used to complement existing methods for treating or preventing iron deficiency.

\section{Acknowledgments}

The authors thank, in the early steps of the human studies, Dr. Tomas Walter, whom, we regret, died recently. The authors also thank Brie K. Fuqua for preparing ferritin with ${ }^{59} \mathrm{Fe}$ for the rat studies. B.E., H.C., F.P., M.T.N., K.S., and E.C.T. designed research; H.C., H.J., C.M., and K.S. performed experiments; H.C., C.M., F.P., M.T.N., and E.C.T. analyzed data; and H.C., F.P., K.S., M.T.N., and E.C.T. wrote the manuscript. All of the authors read and approved the final manuscript.

\section{Literature Cited}

1. Andrews NC, Schmidt PJ. Iron homeostasis. Annu Rev Physiol. 2007;69:69-85.

2. Guo L, Lichten LA, Ryu MS, Liuzzi JP, Wang F, Cousins RJ. STAT5glucocorticoid receptor interaction and MTF-1 regulate the expression of ZnT2 (Slc30a2) in pancreatic acinar cells. Proc Natl Acad Sci USA. 2010;107:2818-23.

3. McKie AT, Barrow D, Latunde-Dada GO, Rolfs A, Sager G, Mudaly E, Mudaly M, Richardson C, Barlow D, Bomford A, et al. An iron regulated ferric reductase associated with the absorption of dietary iron. Science. 2001;291:1755-9.

4. Laftah AH, Latunde-Dada GO, Fakih S, Hider RC, Simpson RJ, McKie AT. Haem and folate transport by proton-coupled folate transporter/ haem carrier protein 1 (SLC46A1). Br J Nutr. 2009;101:1150-6.

5. Liu X, Theil EC. Ferritin: dynamic management of biological iron and oxygen chemistry. Acc Chem Res. 2005;38:167-75.

6. San Martin CD, Garri C, Pizarro F, Walter T, Theil EC, Núñez MT. Caco-2 intestinal epithelial cells absorb soybean ferritin by mu2 (AP2)dependent endocytosis. J Nutr. 2008;138:659-66.

7. Burton JW, Harlow C, Theil EC. Evidence for reutilization of nodule iron in soybean seed development. J Plant Nutr. 1998;21:913-27.

8. Theil EC. Iron, ferritin and nutrition. Annu Rev Nutr. 2004;24:327-43.

9. Lönnerdal B. Soybean ferritin: implications for iron status of vegetarians. Am J Clin Nutr. 2009;89:S1680-5.

10. Kalgaonkar S, Lonnerdal B. Effects of dietary factors on iron uptake from ferritin by Caco-2 cells. J Nutr Biochem. 2008;19:33-9.

11. Kalgaonkar S, Lonnerdal B. Receptor-mediated uptake of ferritinbound iron by human intestinal Caco-2 cells. J Nutr Biochem. 2009;20:304-11.

12. Bates GW, Billups C, Saltman P. The kinetics and mechanism of iron (3) exchange between chelates and transferrin. I. The complexes of citrate and nitrilotriacetic acid. J Biol Chem. 1967;242:2810-5.

13. Schümann K, Elsenhans B, Forth W. Kinetic analysis of $59 \mathrm{Fe}$ movement across the intestinal wall in iron-deficient and iron-adequate duodenal rat segments ex vivo. Am J Physiol. 1999;276:G431-40.

14. Bates GW, Billups C, Saltman P. The kinetics and mechanism of iron(III) exchange between chelates and transferrin. II. The presentation and removal with ethylenediaminetetraacetate. J Biol Chem. 1967;242: 2816-21.

15. Davila-Hicks P, Theil EC, Lonnerdal B. Iron in ferritin or in salts (ferrous sulfate) is equally bioavailable in nonanemic women. Am J Clin Nutr. 2004;80:936-40.
16. Lönnerdal B, Bryant A, Liu X, Theil EC. Iron absorption from soybean ferritin in nonanemic women. Am J Clin Nutr. 2006;83:103-7.

17. Simpson RJ, Peters TJ. Studies of Fe3+-transport across isolated intestinal brush-border membrane in the mouse. Biochim Biophys Acta. 1984;772:220-6.

18. Lopez de Romaña D, Ruz M, Pizarro F, Landeta L, Olivares MA Supplementation with zinc between meals has no effect on subsequent iron absorption or on iron status of Chilean women. Nutrition. 2008;24:957-63.

19. Sammán N, Maldonado S, Alfaro ME, Farfan N, Gutierrez J. Composition of different bean varieties (Phaseolus vulgaris) of Northwestern Argentina (Region NOA): cultivation zone influence. J Agric Food Chem. 1999;47:2685-9.

20. Hoppler M, Zeder C, Walczyk T. Quantification of ferritin-bound iron in plant samples by isotope tagging and species-specific isotope dilution mass spectrometry. Anal Chem. 2009;81:7368-72.

21. Cook JD, Monsen ER. Food iron absorption in man II. The effect of EDTA on absorption of dietary non-heme iron. Am J Clin Nutr. 1976;29:614-20.

22. Eakins JD, Brown DA. An improved method for the simultaneous determinations of 55-iron and 59-iron in blood by liquid scintillation counting. Int J Appl Radiat Isot. 1966;17:391-7.

23. Nadler SB, Hidalgo JU, Bloch T. Prediction of blood volume in normal human adults. Surgery. 1962;51:224-32.

24. Baynes RD, Bothwell TH. Iron deficiency. Annu Rev Nutr. 1990; 10:133-48.

25. Schümann K, Elsenhans B, Ehtechami C, Forth W. Rat intestinal iron transfer capacity and the longitudinal distribution of its adaptation to iron deficiency. Digestion. 1990;46:35-45.

26. Torrance JD, Bothwell TH. A simple technique for measuring storage iron concentrations in formalinised liver samples. S Afr J Med Sci. 1968;33:9-11.

27. Crichton RR, Roman F, Roland F. Iron mobilization from ferritin by chelating agents. J Inorg Biochem. 1980;13:305-16.

28. Núñez MT. Regulatory mechanisms of intestinal iron absorptionuncovering of a fast-response mechanism based on DMT1 and ferroportin endocytosis. Biofactors. 2010;36:88-97.

29. Núñez MT, Tapia V, Rojas A, Aguirre P, Gomez F, Nualart F. Iron supply determines apical/basolateral membrane distribution of intestinal iron transporters DMT1 and ferroportin 1. Am J Physiol Cell Physiol. 2010;298:C477-85.

30. Theil EC. Iron homeostasis and nutritional iron deficiency. J Nutr. 2011; 141:S724-8.

31. Han J, Seaman WE, Di X, Wang W, Willingham M, Torti FM, Torti SV. Iron uptake mediated by binding of $\mathrm{H}$-ferritin to the TIM-2 receptor in mouse cells. PLoS ONE. 2011;6:e23800.

32. Nemeth E, Tuttle MS, Powelson J, Vaughn MB, Donovan A, Ward DM, Ganz T, Kaplan J. Hepcidin regulates cellular iron efflux by binding to ferroportin and inducing its internalization. Science. 2004;306:2090-3.

33. Ganz T. Cellular iron: ferroportin is the only way out. Cell Metab. 2005;1:155-7.

34. Murray-Kolb LE, Welch R, Theil EC, Beard JL. Women with low iron stores absorb iron from soybeans. Am J Clin Nutr. 2003;77:180-4.

35. Salgado JC, Olivera-Nappa A, Gerdtzen ZP, Tapia V, Theil EC, Conca C, Nunez MT. Mathematical modeling of the dynamic storage of iron in ferritin. BMC Syst Biol. 2010;4:147.

36. Vanoaica L, Darshan D, Richman L, Schumann K, Kuhn LC. Intestinal ferritin $\mathrm{h}$ is required for an accurate control of iron absorption. Cell Metab. 2010;12:273-82.

37. Orozco MN, Solomons NW, Schumann K, Friel JK, de Montenegro AL. Antioxidant-rich oral supplements attenuate the effects of oral iron on in situ oxidation susceptibility of human feces. J Nutr. 2010;140:1105-10.

38. Werner T, Hoermannsperger G, Schuemann K, Hoelzlwimmer G, Tsuji $S$, Haller D. Intestinal epithelial cell proteome from wild-type and TNFDeltaARE/WT mice: effect of iron on the development of chronic ileitis. J Proteome Res. 2009;8:3252-64. 